\title{
POLÍTICAS DE ALFABETIZAÇÃO, CULTURA PEDAGógICA E CONHECIMENTO LINGUÍSTICO: diálogos com a formação do alfabetizador
}

\author{
Benedita de Almeida \\ Universidade Estadual do Oeste do Paraná (UNIOESTE)
}

POLÍTICAS DE ALFABETIZAÇÃO, CULTURA PEDAGÓGICA E CONHECIMENTO LINGUíSTICO: diálogos com a formação do alfabetizador

Resumo: $O$ artigo apresenta resultados de pesquisa sobre alfabetização, com professores egressos de curso de Pedagogia, no contexto da ampliação do ensino fundamental e das políticas educacionais de gestão, filiadas à nova ordem mundial. Pela perspectiva histórico-cultural da linguagem e do desenvolvimento humano, analisa elementos dessa ampliação e significados do ensino de língua materna nos anos iniciais da escolarização. Realizada com questionários e análise de documentos, seus resultados evidenciam aspectos epistemológicos e políticos desse ensino; destacam os conhecimentos linguísticos expressos pelos sujeitos e o desafio da definição dos conteúdos de ensino da área; apontam fragilidades na relação dos professores com os conhecimentos específicos do campo; e um conflito entre necessidades de formação linguística nos anos iniciais do EF e as possibilidades dos professores que a efetuam, indicando necessidade de conjugação de políticas públicas vigorosas de formação de professores e de estruturação curricular, para a escola poder atuar no desenvolvimento linguístico de professores e estudantes.

Palavras-chave: Políticas educacionais, alfabetização, formação de professores.

ALPHABETIZATION, PEDAGOGICAL CULTURE AND LANGUAGE KNOWLEDGE POLITICS: dialogues with the teacher's education

Abstract: This article presents results on an alphabetization research, conducted with teachers graduated in Pedagogy courses, in the context of expansion of elementary school and educational policies for management, affiliated to new world ordaining. Historical and cultural perspective of language and human development, analyzes the elements of such an enlargement and the meanings of teaching the mother language in the early years of school. This research was conducted with the use of questionnaires and documentation analysis, and its results highlight the political and epistemological aspects of elementary school, with emphasis in language knowledge as expressed by the research subjects and the challenge of definition the teaching content in this context. It also uncovers some fragilities in the teacher's relationship with their specific knowledge, and a conflict between their needs for linguistic formation in the early years of school and the teachers' possibilities in their field, thus indicating that there is a need of conjugating of vigorous public policies of teachers' formation and curricular structure so that the school can actively work on the linguistic development of both teachers and students that the first years of school pose.

Key words: Educational policies, alphabetization, teachers' formation. 


\section{INTRODUÇÃO}

O sistema educacional brasileiro tem convivido com políticas que nem sempre primam pela relação entre qualidade e quantidade e que significaram, em curto prazo, o aumento do número de alunos nas escolas, mesmo não acompanhado de condições apropriadas ao bom atendimento (ARELARO, 2005). Recursos financeiros, formação de professores e condições político-pedagógicas, muitas vezes, caminham em descompasso com as necessidades da área.

No empenho para superar resultados educativos negativos, entre outras medidas, por alteração da Lei de Diretrizes e Bases da Educação Nacional (LDB), Lei n 9.394, de 20 de dezembro de 1996, institui-se, em 2006, a duração de nove anos para o ensino fundamental (EF) "[...] obrigatório, gratuito na escola pública, iniciando-se aos 6 (seis) anos de idade [...]", com o objetivo de proporcionar a "[...] formação básica do cidadão [...]" (BRASIL, 2006). Na realidade brasileira, em que muitas crianças iniciam relações com as práticas culturais letradas e o conhecimento sistematizado apenas com o ingresso na escola, a ampliação do tempo de escolarização obrigatória anuncia-se como medida positiva. Como a totalidade das relações culturais é determinante da formação humana, a escola constitui situação que disponibiliza ação, tempo e outros recursos para os sujeitos se apropriarem dos instrumentos culturais da humanidade, que não seriam acessíveis de outra forma e sem a mediação do ensino (VIGOTSKI, 1998).

São nessa perspectiva as reflexões de Davídov (1988), para quem, com o ingresso na escola e a realização da atividade de estudo ${ }^{1}$ destinada ao domínio de conhecimentos e capacidades relacionados ao pensamento teórico, formam-se, nas crianças, as bases da relação teórica face à realidade. Pela atividade de estudo, as crianças reproduzem os conhecimentos e habilidades relativos aos fundamentos da consciência social e também as capacidades surgidas historicamente e situadas na base da consciência e do pensamento teórico ${ }^{2}$, como reflexão, análise e experimento mental ${ }^{3}$. A atividade de estudo tem conteúdo (conhecimentos teóricos ${ }^{4}$ ) e estrutura especiais que a diferenciam das outras atividades próprias às crianças, implica específicos e necessários níveis de consciência sobre o pensamento, diferentes daqueles necessários às outras atividades que a criança realiza. É, também, responsável pelo surgimento das principais neoformações psicológicas da idade, define o desenvolvimento psíquico geral dos escolares de menor idade e a formação de sua personalidade, em conjunto. É esse desenvolvimento que permite ao homem sair do limite do cotidiano observável diretamente (empírico) e o introduz no pensamento abstrato, mediado por relações (DAVÍDOV, 1988).

Para esse estudioso do desenvolvimento humano, o início do ensino e da educação escolar constitui momento de transformações fundamentais na vida da criança, cujos principais fundamentos são internos, ocorrem com a assimilação das formas mais desenvolvidas da consciência social: a ciência, a arte, a moral, o direito, formas ligadas à consciência e ao pensamento teórico dos sujeitos.

A aprendizagem formal disponibilizada na escola, pela apropriação de conceitos científicos ${ }^{5}$, é determinante ao desenvolvimento das funções psicológicas superiores, porque a aprendizagem de conteúdos específicos leva ao desenvolvimento de funções mentais específicas. O ambiente sociocultural gerado na escola e a organização adequada da ação educativa escolar movimentam processos internos do indivíduo e podem gerar desenvolvimento (VIGOTSKI, 2009), o que faz da ampliação temporal um ponto promissor dessa reforma.

Este trabalho trata do ensino de língua materna (LM) nos anos iniciais do EF, analisa documentos da política de ampliação dessa etapa escolar, os conteúdos dessa área ensinados nos anos iniciais e os conhecimentos linguísticos dos professores. Os dados da pesquisa foram obtidos por questionários a vinte e um professores graduados entre 2002 e 2007, no curso de Pedagogia da Universidade Estadual do Oeste do Paraná, campus de Francisco Beltrão, PR, que exerciam a docência, no ano de 2009, em escolas públicas do município.

De início, discutem-se as relações entre ampliação do EF e ensino de LM nos anos iniciais, com fundamentos em categorias do trabalho linguístico escolar, na perspectiva histórico-cultural, e os limites intrínsecos dessa política à ampliação do direito à educação. Na sequência, analisam-se o conceito de conteúdos de ensino e os conteúdos de LM ensinados, relacionados ao conhecimento linguístico do alfabetizador. Nas reflexões finais, discute-se a relação de políticas educacionais com a cultura pedagógica da alfabetização e a formação do alfabetizador em curso de Pedagogia.

\section{AMPLIAÇÃO DO ENSINO FUNDAMENTAL E ENSINO DE LÍNGUA MATERNA NOS ANOS INICIAIS}

Um princípio essencial ao ensino da língua na escola é sua função de contribuir para ampliar a capacidade de interpretação da realidade, para que os sujeitos se ponham em contato com a cultura, na totalidade, e rompam os limites do senso comum. Trata-se de considerar a alfabetização como educação linguística com papel decisivo no desenvolvimento do sujeito, na proporção em que contribua à emersão de capacidades de compreensão, de análise e de crítica; como instrumento de emancipação, direcionado à transformação da realidade. No âmbito específico da alfabetização, histórico problema da educação brasileira, a ampliação do EF pretende incidir na maior distribuição social da leitura e escrita, práticas 
cujo domínio se caracteriza como forte mecanismo de inclusão (FRADE, 2007).

Somente a ampliação do tempo de escolarização, contudo, não garante melhoria da qualidade do ensino, como processo científico e humanizador. Não implica "[...] democracia social ou redução das desigualdades." (BRITTO, 2007, p. 23). Muitos problemas educacionais têm raízes de ordem social e política, pela falta de acesso a bens culturais, como a escrita, entre outros determinantes. Além da ampliação do tempo, há que se garantir o exercício do direito à alfabetização, permanência na escola, continuidade dos estudos e melhoria da qualidade social e científica da educação - ações que requerem outras políticas e ações.

$\mathrm{Na}$ implantação do EF de nove anos, no estado do Paraná, a discussão ficou restrita à idade de ingresso na escola, envolveu decisões judiciais ${ }^{6}$, e foram marginalizadas questões fundamentais sobre a ampliação da escolaridade, o papel da escola, do ensino em geral e da alfabetização, em particular. A ampliação do tempo de escolaridade, elemento propalado entre os objetivos dessa política e relacionado à ampliação do direito à educação pode ser questionada nas redes de ensino que atendem a duas condições: permissão do ingresso da criança de cinco anos no primeiro ano e oferta de educação infantil, para, pelo menos, a partir dos quatro anos de idade. Como mostra a Tabela 1, linha 4 (L4), essa criança terá suprimido um ano do período da educação infantil, em relação àquela que ingressa com seis anos de idade (L3). Se considerarmos o ingresso na educação infantil aos quatro anos de idade, a primeira (L4) terá treze anos de escolaridade, na educação básica, e a segunda (L3), quatorze.

Essa condição não corresponde ao praticado por muitos municípios brasileiros. Para aqueles municípios com problemas no acesso à educação infantil, oganhoemaumento dotempo de escolaridade para a criança é real e deverá resultar em reflexos na organização e prática da alfabetização. Quando o acesso à educação infantil é, pelo menos, a partir dos quatro anos de idade, o efeito é contrário, perde-se um ano de escolaridade (L4). No caso das crianças de classes menos favorecidas e escasso convívio com práticas letradas - aquelas que deveriam ser beneficiadas pela reforma - esse fator poderá ser negativo, portanto.
Para Maciel, Baptista e Monteiro (2009), a ampliação de vagas no EF é fator do exercício do direito à educação, mas é no âmbito das práticas pedagógicas que se encontram condições para expressão desse direito, pelo ensino e aprendizagem. Assim, vale ressaltar alguns desafios propostos à alfabetização pela ampliação do EF e incidentes nessa dimensão: falta de clareza sobre o que ensinar no primeiro ano, imprecisão que se expandiu a toda etapa inicial; desconsideração de especificidades da faixa etária ${ }^{7}$ no trabalho pedagógico; e desenvolvimento de práticas instrumentais. Desarticulados de fundamentos, os objetivos de alfabetização tornam-se ambíguos, e as práticas, ativismos.

O ensino de LM, no Brasil, é objeto de muitas críticas, pelos problemáticos desempenhos em leitura e escrita de estudantes e na sociedade em geral, mesmo em segmentos da população com alto nível de escolaridade. Essa questão desafia a organização de políticas educacionais e é reiterada em pesquisas que situam o país em posições insatisfatórias. Como exemplo, destaca-se o Programa Internacional de Avaliação de Alunos (PISA), avaliação internacional do nível educacional, realizada a cada três anos com jovens de 15 anos, por provas de leitura, matemática e ciências, para produzir indicadores sobre a educação básica e subsidiar políticas de melhoria educacional. Em 2009, o Brasil ocupou a $49^{a}$ posição (INSTITUTO NACIONAL DE ESTUDOS E PESQUISAS EDUCACIONAIS ANÍSIO TEIXEIRA, 2011). O Brasil possui também um sistema de avaliação consolidado e periodicizado, a cargo do Instituto Nacional de Estudos e Pesquisas Educacionais Anísio Teixeira (INEP), que afere e divulga o Índice de Desempenho da Educação Básica (IDEB). Embora possam sinalizar aspectos das aprendizagens da escrita, não defendemos seu uso ou legitimidade, pois a questão envolve aprofundados estudos sobre as características e materialidades dessas avaliações, suas tendências de homogeneização cultural e de direcionamento do ensino, mas, principalmente, sobre o projeto social e político que as orientam.

O uso da escrita dota os sujeitos de um importante instrumental para sua formação, porque a escola se suporta na cultura gráfica; as práticas da escrita os põem em contato com a produção cultural humana e possibilitam relações com o

Tabela 1 - Distribuição dos anos/séries escolares e idade cronológica por idade de ingresso no EF

\begin{tabular}{l|l|c|c|c|c|c|c|c|c|c|c|c|c|c|c|c}
\hline L1 & $\begin{array}{l}\text { EF 08 anos } \\
\text { (Séries) }\end{array}$ & & & & & $1^{\circ}$ & $2^{\circ}$ & $3^{\circ}$ & $4^{\circ}$ & $5^{\circ}$ & $6^{\circ}$ & $7^{\circ}$ & $8^{\circ}$ & $1^{\circ}$ & $2^{\circ}$ & $3^{\circ}$ \\
\hline L2 & Idades cronológicas & $0-3$ & 04 & 05 & 06 & 07 & 08 & 09 & 10 & 11 & 12 & 13 & 14 & 15 & 16 & 17 \\
\hline L3 & $\begin{array}{l}\text { EF 09 anos } \\
\text { (Anos/Séries) Ingresso } \\
\text { aos } 6 \text { anos }\end{array}$ & $\mathrm{El}$ & $\mathrm{El}$ & $\mathrm{El}$ & $1^{\circ}$ & $2^{\circ}$ & $3^{\circ}$ & $4^{\circ}$ & $5^{\circ}$ & $6^{\circ}$ & $7^{\circ}$ & $8^{\circ}$ & $9^{\circ}$ & $1^{\circ}$ & $2^{\circ}$ & $3^{\circ}$ \\
\hline $\mathrm{L} 4$ & $\begin{array}{l}\text { EF 09 anos (Anos/Séries) } \\
\text { Ingresso aos 5 anos }\end{array}$ & $\mathrm{El}$ & $\mathrm{EI}$ & $1^{\circ}$ & $2^{\circ}$ & $3^{\circ}$ & $4^{\circ}$ & $5^{\circ}$ & $6^{\circ}$ & $7^{\circ}$ & $8^{\circ}$ & $9^{\circ}$ & $1^{\circ}$ & $2^{\circ}$ & $3^{\circ}$ & \\
\hline
\end{tabular}

Fonte: Elaborada pela autora. 
conhecimento sistematizado. Diferentemente da oralidade, requerem ensino explícito e direto para apreensão de sua técnica de funcionamento, uma das dimensões de seu aprendizado. Talvez a mais evidente, com certeza, indispensável, mas não suficiente para apreensão e usufruto das relações, significados e benefícios da cultura escrita. Muito além da dimensão técnica, a escrita constitui um sistema simbólico que atua na relação do homem com o mundo, como atividade mediadora na apreensão do real, portanto como função do pensamento (VIGOTSKI, 2009).

Nessa perspectiva histórico-cultural, não se pressupõem níveis hierárquicos de valoração entre oralidade e escrita, mas se reconhece que seus usos, as formas de sua produção, as estratégias necessárias e a posição contextual do sujeito, em presença ou ausência dos interlocutores, marcam diferenças significativas entre ambas. Tais diferenças são, também, relacionadas ao tipo de simbolismo que constitui as duas modalidades da linguagem. Vigotski (2000, p. 183) concebe a escrita como um "[...] sistema especial de símbolos e signos cujo domínio significa uma mudança crítica $^{8}$ em todo o desenvolvimento cultural da criança." Para o autor, a escrita

\begin{abstract}
[...] é formada por um sistema de signos que identifica convencionalmente os sons e as palavras da linguagem oral que são, por sua vez, signos de objetos e relações reais. O nexo intermediário [...], a linguagem oral pode extinguir-se gradualmente, e a linguagem escrita se transforma em um sistema de signos que simboliza diretamente os objetos designados, assim como suas relações recíprocas. (VIGOTSKI, 2000, p. 184).
\end{abstract}

Por essa constituição sígnica, o aprendizado da escrita movimenta capacidades intelectuais dos indivíduos e desenvolve-as. Esse aprendizado se situa num campo de produção e circulação de significados, por uma dupla via: (i) a das características mediadoras da linguagem na relação do homem com o mundo, e (ii) a dos conteúdos ideológicos que transitam nas palavras e que atuam na formação da consciência e suas formas de compreensão da realidade, pois carregam os sentidos sociais circulantes (LEONTIEV, 1988; LURIA, 1988; BAKHTIN, 2002). Ou seja, a aprendizagem de escrita e leitura não se reduz à questão físico-motora, nem à utilitarista-pragmática. Mais que isso, refere-se à constituição de conhecimentos, ao desenvolvimento da função intelectual, por isso, com atuação na formação da identidade, pois,

[...] na realidade, não são palavras o que pronunciamos ou escutamos [ou escrevemos e lemos], mas verdades ou mentiras, coisas boas ou más, importantes ou triviais, agradáveis ou desagradáveis, etc. (BAKHTIN, 2002, p. 95).

Tais elementos têm desdobramentos na definição e ensino dos conteúdos de LM nos anos iniciais do EF, nas suas relações com os objetivos de ensino linguístico e, principalmente, com os saberes dos professores, para poderem desenvolver habilidades fundamentais à inserção dos educandos na cultura escrita.

A definição dos conteúdos a serem ensinados nas aulas de alfabetização e língua portuguesa articula-se diretamente aos objetivos de ensino da área e é questão recorrente nas discussões de professores, pesquisadores e organizadores de políticas educacionais. Constitui, no entanto, uma questão instável, cercada de incertezas e dúvidas dos professores, muitas vezes tratada na dimensão do senso comum. O que ensinar nas aulas de língua materna? Que dimensões devem ser focalizadas? Que conhecimentos são necessários ensinar e aprender? O que significa ensinar a escrita? Qual o papel da gramática e como deve ser ensinada, considerando a linguagem como elemento de interação social? Que conteúdos de ensino permitiriam organizar uma prática voltada à dinâmica da linguagem? Mesmo com os avanços nos estudos das questões conceituais e metodológicas que envolvem a alfabetização e sua universalização, ainda persistem desafios a serem superados. Vencer situações de fracasso da escola em desempenhar seu papel no ensino da língua escrita como prática social de interação, relacionada ao desenvolvimento do pensamento autônomo, pode ser o principal e sintetiza muitos âmbitos envolvidos na problemática. Outros desafios perpassam o campo, como os relativos aos vínculos que se estabelecem entre os sujeitos em aprendizagem e a escrita. Vínculos que podem significar a apreensão da escrita como forma de dizer a sua palavra ou reproduzir a alheia, com os laivos de autoritarismo envolvidos nisso.

$\mathrm{Na}$ perspectiva de ampliar a compreensão sobre o ensino de LM na nova organização dos anos iniciais do EF, na relação com a formação de professores, na sequência, focalizam-se os conteúdos de ensino e os conhecimentos expressos pelos sujeitos da pesquisa sobre a área.

\section{CONTEÚDOS DE ENSINO E CONHECIMENTOS LINGUÍSTICOS DOS PROFESSORES: desafios} no ensino

A definição de conteúdos de ensino de uma área, para os anos escolares, é elemento complexo da organização educativa. É decisão relacionada diretamente à clareza sobre a função que se espera ser cumprida por esse conteúdo, "[...] em relação aos indivíduos, à cultura herdada, à sociedade na qual estamos e à qual aspiramos conseguir." (GIMENO 
SACRISTÁN, 1998, p. 149). Os conteúdos são uma construção social que refletem um projeto de sociedade; expressam valores dessa sociedade, nos momentos históricos, e são determinados pelas condições sociais, culturais, históricas e políticas que afetam a escola. Seu escopo é amplo,

[inclui] todas as aprendizagens que os alunos devem alcançar para progredir nas direções que marcam os fins da educação numa etapa de escolarização, em qualquer área ou fora delas, e para tal é necessário estimular comportamentos, adquirir valores, atitudes e habilidades de pensamento, além de conhecimentos. (GIMENO SACRISTÁN, 1998, p. 150).

Observe-se a importante dimensão do ensino, o desenvolvimento das habilidades de pensamento, modos de perceber os objetos estudados, a partir das categorias conceituais que os constituem e por intermédio da reflexão propiciadora de compreensão desse objeto na totalidade - modos de pensar que tomam o próprio pensamento como objeto. No caso da alfabetização, refere-se a uma compreensão que reconheça a realidade fundamental da língua no "[...] fenômeno social da interação verbal, realizada através da enunciação."; compreensão que reconheça que

[...] a verdadeira substância da língua não é constituída por um sistema abstrato de formas linguísticas, nem pela enunciação monológica isolada, nem pelo ato psicofisiológico de sua produção. (BAKHTIN, 2002, p. 123).

A área de LM é tópico destacado nas regulamentações oficiais do EF. Apontada como instrumento para a escolarização, tem tempo privilegiado nos anos iniciais, como meio básico para ampliação do processo educativo (BRASIL, 2010), o que a torna uma ênfase formativa. Recebe, também, destaque em carga horária e ocupação efetiva das atividades escolares. O fato de a escrita organizar, concretizar e mediar a maioria dos processos realizados na escolarização concede-lhe relevância para a mediação com conhecimentos. Sem pretender hierarquizar disciplinas ou áreas de conhecimento, reconhece-se que o aprendizado da língua escrita dota a criança de um importante instrumental para dar conta de suas atividades no início e prosseguimento da vida escolar. Do mesmo modo, os problemas derivados do seu (não) aprendizado representam importantes contornos no desempenho geral do estudante.

A finalidade do ensino e aprendizado de LM, na escola, é ampliar a capacidade do sujeito de operar concretamente com oralidade, leitura e escrita, operação que implica a expressão linguística, a compreensão, a reflexão sobre a língua, o conhecimento dos recursos linguísticos necessários à compreensão e produção dos diferentes discursos ${ }^{9}$ nas diferentes esferas da prática social.

$\mathrm{Na}$ pesquisa, foram feitas duas perguntas aos professores: uma, solicitando os

principais conteúdos de LM ensinados por eles, outra, sobre quais os conhecimentos necessários ao professor, para poder ensinar LM, nos anos iniciais. Os resultados estão agrupados em dois eixos conteúdos ensinados e conhecimentos essenciais ao professor. Na análise, cabe destacar que os dados foram obtidos por questionários, portanto, podem conter aspectos do nível de idealização dos sujeitos sobre o ensino ${ }^{10}$. De todo modo, as manifestações representam o que consideram importante ensinar e a relevância dos conteúdos.

No momento da pesquisa, os três primeiros anos funcionavam na organização do EF em 09 anos, e os dois últimos, na de 08 anos. A Tabela 2 apresenta a distribuição dos 21 sujeitos pelas turmas de alunos.

No Quadro 1, seguinte, apresentam-se os conteúdos ensinados e os conhecimentos essenciais informados pelos sujeitos, separados por ano (série) de escolaridade.

Os conteúdos estão apresentados na forma como foram enunciados, repetindo-se os semelhantes e quantificando os com mais de uma ocorrência. Pode-se observar que a quantidade de sujeitos interfere na quantidade de conteúdos. $\mathrm{Na}$ maioria das vezes, não foram informados os mesmos conteúdos por todos os sujeitos de um mesmo ano escolar.

No $1^{\circ}$ ano, entre os conteúdos ensinados, estão presentes os relacionados às aprendizagens requeridas para alfabetização, na sua dimensão técnica, na simbólica e na de elaboração do pensamento, embora a primeira sobressaia. Há menção ao conhecimento de símbolos (apenas 01, entre os 08 sujeitos), sons, letras, palavras etc., referentes às habilidades de decodificar símbolos escritos e codificá-los. O aprendizado da escrita e de suas funções sociais é frequente, mais que o da leitura e oralidade; e a compreensão é destacada. Gramática e ortografia também são mencionadas, para $01^{\circ}$ ano, e há reproduções dos eixos do

Tabela 2 - Caracterização dos sujeitos pelos anos/séries de ensino ${ }^{11}$

\begin{tabular}{c|c|c|c|c|c|c|c}
\hline EF-09 anos & $1^{\circ}$ ano & $2^{\circ}$ ano & $3^{\circ}$ ano & - & Todal \\
\hline EF-08 anos & - & - & - & $3^{a}$ série & $4^{a}$ série & Todos & 02 \\
\hline Professores & 08 & 03 & 04 & 00 & 02 & $\mathbf{2 1}$ \\
\hline
\end{tabular}

Fonte: Elaborada pela autora. 
Quadro 1 - Conteúdos ensinados e conhecimentos linguísticos essenciais ao professor: $1^{\circ}, 2^{\circ}$ e $3^{\circ}$ anos (ciclo da alfabetização)

\begin{tabular}{|c|c|c|}
\hline $1^{\circ}$ Ano - 08 Sujeitos & $2^{\circ}$ Ano - 03 Sujeitos & $3^{\circ}$ Ano - 01 Sujeito \\
\hline 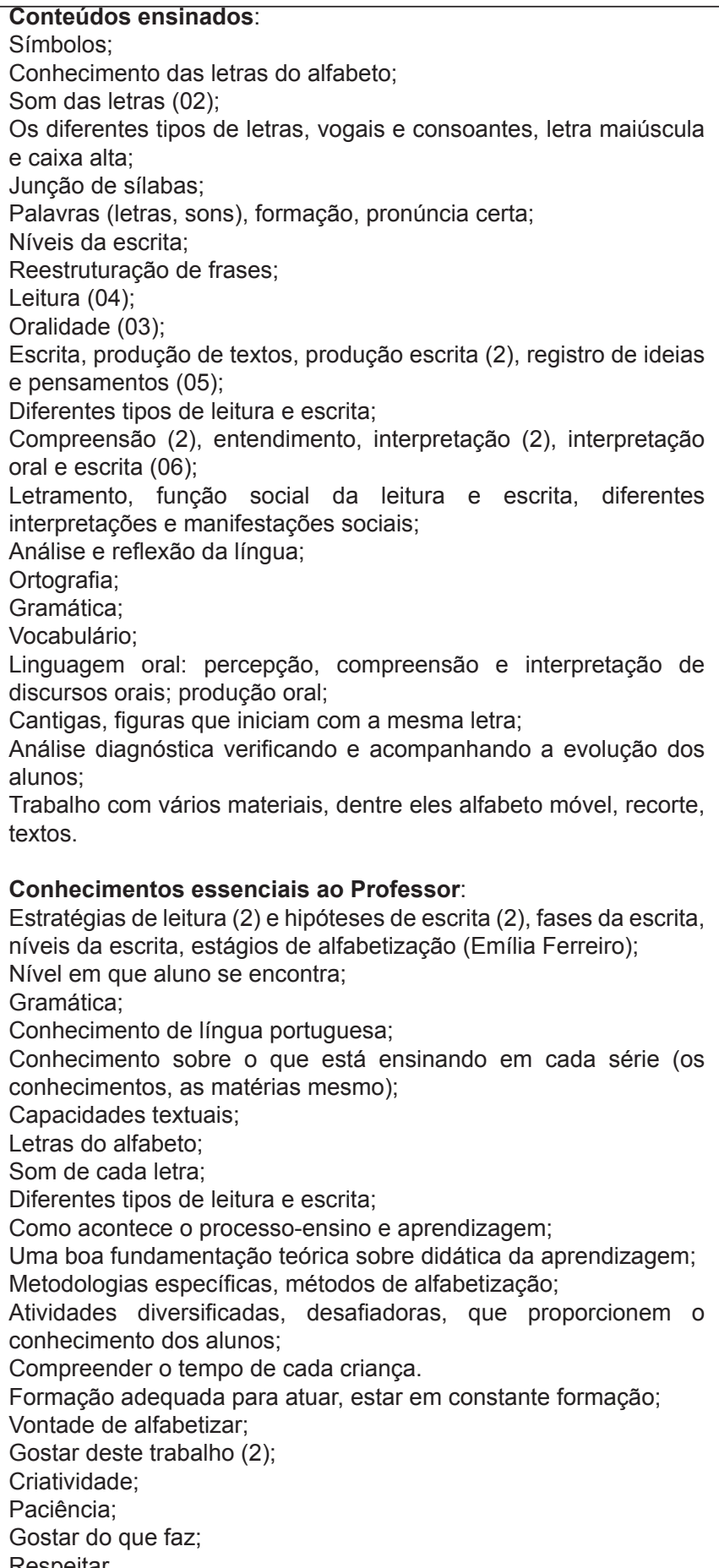 & $\begin{array}{l}\text { Conteúdos ensinados: } \\
\text { A iniciação de letras, palavras, } \\
\text { etc., maiúscula, minúscula; } \\
\text { Escrita, produção de textos; } \\
\text { Todos relacionados ao início } \\
\text { da compreensão da escrita; } \\
\text { Compreensão, interpretação } \\
\text { de diversos portadores de } \\
\text { textos; } \\
\text { Oralidade; } \\
\text { Expressão; } \\
\text { Gramática, gramática num } \\
\text { todo, principalmente em forma } \\
\text { de redação; } \\
\text { Substantivos (etc.); } \\
\text { Pontuação. } \\
\text { Conhecimentos essenciais } \\
\text { ao Professor: } \\
\text { Compreender como } \\
\text { aluno entende e processa } \\
\text { o conhecimento da língua } \\
\text { portuguesa, conhecer bem e } \\
\text { saber como a criança aprende } \\
\text { em cada fase e saber usar isto } \\
\text { de acordo com as propostas } \\
\text { da escola; } \\
\text { Ter clareza de como trabalhar } \\
\text { com a criança; } \\
\text { Leitura; } \\
\text { Produção de texto; } \\
\text { Interpretação textual (o aluno } \\
\text { precisa entender o que lê e não } \\
\text { apenas decodificar as letras). }\end{array}$ & $\begin{array}{l}\text { Conteúdos ensinados: } \\
\text { Produção escrita; } \\
\text { Leitura; } \\
\text { Interpretação } \\
\text { compreensão; } \\
\text { Variedade de gêneros } \\
\text { textuais. } \\
\text { Conhecimentos essenciais } \\
\text { ao Professor: } \\
\text { Metodologias que usa; } \\
\text { Formas de priorizar a } \\
\text { aprendizagem a todos, } \\
\text { proporcionar atividades } \\
\text { adequadas, pois nem todos } \\
\text { estão no mesmo nível de } \\
\text { aprendizagem. }\end{array}$ \\
\hline
\end{tabular}

Fonte: Elaborado pela autora.

Pró-letramento (BRASIL, 2008) e de elementos da psicogênese da escrita, que não constituem conteúdos, mas teoria sobre o processo de aquisição da escrita. Metodologias, atividades e materiais são incluídos como conteúdos.

Entre os conhecimentos essenciais ao alfabetizador, poucos estão nas duas condições - a de ensinados e a de essenciais. Os aspectos relacionados à psicogênese repetem-se como os mais frequentes, um possível resultado das políticas de formação continuada do alfabetizador, nos últimos anos. Muitos elementos citados não se referem a conhecimentos, e vários são relacionados ao âmbito das disposições do indivíduo. Alguns se remetem, especificamente, ao conhecimento linguístico, mas de um modo generalizante, como gramática, conhecimento de língua portuguesa, e outros relativos às aprendizagens básicas da alfabetização. São importantes, embora revelem uma percepção muito ampla e inespecífica do objeto de ensino, 
portanto, não favorável ao trabalho pedagógico. O grande foco em metodologias de trabalho, em atividades e em teorias da aprendizagem indica maior ênfase ao conhecimento didático e pedagógico, em detrimento do saber disciplinar específico da área, os conhecimentos linguísticos.

No caso específico da alfabetização, os conhecimentos essenciais do professor relacionados aos fatores de desenvolvimento envolvidos na apropriação da escrita, pela própria compreensão desse sistema, não estão presentes. Segundo Luria (1988), para ser capaz de escrever algo, a criança precisa empregar signos - elementos que não têm sentido em si mesmos, mas remetem ao objeto da realidade. Para operar com signos, o sujeito precisa ter desenvolvido a relação funcional, relação que se remete às formas superiores do comportamento infantil, pois implica o desenvolvimento de processos de representação mediados que permitem operar mentalmente sobre o real, mesmo em sua ausência. Somente quando a criança desenvolveu a relação funcional com as coisas, "[...] é que podemos dizer que as complexas formas intelectuais do comportamento humano começaram a se desenvolver." (LURIA, 1988, p.145). Constituindo-se num novo instrumento do pensamento, o desenvolvimento da escrita suscita o aparecimento de novas estruturas mentais, aspecto praticamente ausente nas respostas.

Para $02^{\circ}$ ano, período em que as aprendizagens sistemáticas da escrita começam a ser consolidadas, na perspectiva de desenvolver e ampliar o comportamento de leitor e o conhecimento de como os indícios linguísticos atuam na expressão e compreensão do sentido (CHARMEUX, 1994), as informações sobre os conteúdos ensinados mostram uma carência de objetos. Destacam-se o trabalho com texto, a ausência da leitura, e, além de referências ao ensino de letras, de gramática, continuam as expressões inespecíficas sobre o conhecimento ensinado.
Nos conhecimentos essenciais para o professor, quase não os há relativos à língua, propriamente dita. A maioria refere-se a como a criança aprende, fator que parece evidenciar uma visão salvacionista sobre tais teorias. Como se esse conhecimento (e das metodologias, também ressaltadas nas respostas) fosse suficiente para alfabetizar bem. Percebe-se uma desconsideração ou desvalorização dos conhecimentos específicos e fundamentais da educação linguística na escola.

Em relação ao $3^{\circ}$ ano do ciclo de alfabetização, ainda etapa de consolidação e sistematização das aprendizagens sobre o sistema de escrita, os conteúdos ensinados também se constituem pelas grandes dimensões do ensino de LM: escrita, leitura, interpretação. Destaque-se a inclusão do trabalho com texto. Para essa etapa, os conhecimentos essenciais informados reduzem-se ao didáticopedagógico e às teorias da aprendizagem.

Os conteúdos expressos pelos professores do $4^{\circ}$ ano e dos que lecionaram em todos os anos iniciais estão sistematizados no Quadro 2.

Para o $4^{\circ}$ do EF, os destaques dos conteúdos ensinados são para elementos gerais que constituem grandes eixos de conteúdos presentes no manual do Pró-letramento (BRASIL, 2008), sem detalhar conteúdos específicos. Esse detalhamento individual é imprescindível, para definir quais os conhecimentos relativos àquele momento do processo de ensino e aprendizagem, portanto, para objetivar o campo do ensino. Outros se limitam às dimensões amplas de oralidade, leitura, escrita, alfabetização e letramento, mas não se evidenciam os conhecimentos necessários ao aprendizado dessas práticas.

Para esse grupo, os conhecimentos essenciais do professor também se reduzem a argumentos do Pró-letramento, à expressão generalizante sobre conteúdos em si, ao âmbito pedagógico e relacional, sem especificar conhecimentos. Apontam-se

Quadro 2 - Conteúdos ensinados e conhecimentos linguísticos essenciais ao professor: $4^{\circ}$ ano e professores que lecionaram em todos os anos iniciais

\begin{tabular}{|c|c|}
\hline $4^{\circ}$ Ano - 02 Sujeitos & Todos os Anos - 04 Sujeitos \\
\hline $\begin{array}{l}\text { Conteúdos ensinados: } \\
\text { Compreensão e valorização da escrita; apropriação } \\
\text { do sistema de escrita; leitura; produção de textos; } \\
\text { desenvolvimento da oralidade. Ob.: repetição de eixos } \\
\text { do manual Pró-Letramento (BRASIL, 2008); } \\
\text { Leitura; escrita; oralidade; alfabetização e letramento. } \\
\text { Conhecimentos essenciais ao Professor: } \\
\text { Compreensão dos processos envolvidos na aquisição } \\
\text { do sistema de escrita alfabético e das capacidades } \\
\text { necessárias ao aluno para o domínio da leitura, da } \\
\text { produção de textos orais e escritos Ob.: repetição de } \\
\text { eixos do manual Pró-Letramento (BRASIL, 2008); } \\
\text { Conhecimento dos conteúdos, das várias formas de } \\
\text { aprendizado do aluno de didáticas diferenciadas, } \\
\text { de materiais concretos variados, de psicologia de } \\
\text { relacionamento. }\end{array}$ & $\begin{array}{l}\text { Conteúdos ensinados: } \\
\text { Leitura (03); } \\
\text { Escrita (02); } \\
\text { Relato de fatos vividos e imaginados, segmentação e sequência de ideias; } \\
\text { Na alfabetização: as letras do alfabeto, sílabas, encontros vocálicos, } \\
\text { consonantais, ditongo, tritongo, formação de frases, estrutura de texto, } \\
\text { parágrafo, coesão e coerência. Diferentes tipos de textos (informativo, } \\
\text { literário, jornalístico, etc.), leitura, aquisição de novas palavras. } \\
\text { Língua Portuguesa estrutura de texto, coesão e coerência, ortografia, } \\
\text { artigos, verbos, pronomes, concordância verbal, plural e singular, oxítona, } \\
\text { paroxítona, proparoxítona, etc., linguagem formal e informal e variedade } \\
\text { linguística. } \\
\text { Conhecimentos essenciais ao Professor: } \\
\text { Como a criança se apropria dos conhecimentos científicos; } \\
\text { Como a criança se apropria da linguagem; } \\
\text { O que a linguagem representa e significa no desenvolvimento da criança; } \\
\text { Como se dá o processo de aquisição da linguagem pela criança; } \\
\text { Linguagem oral e escrita; } \\
\text { Análise e reflexão da [sic] língua. }\end{array}$ \\
\hline
\end{tabular}

Fonte: Elaborado pela autora. 
elementos importantes do ensino em geral, mas não específicos e necessários da área linguística.

No grupo de sujeitos que já lecionaram em todos os anos, três sujeitos encontravam-se em função de coordenação pedagógica, e suas informações seriam importantes pela possibilidade de referência ao conjunto dos anos iniciais, podendo apresentar uma visão da totalidade dos conteúdos ensinados nessa etapa do ensino fundamental. Indicam, no entanto, apenas as grandes dimensões do ensino de língua materna, sem especificar conteúdos. O conjunto de respostas do quarto sujeito, que também atuou em vários anos, mostra um detalhamento de conteúdos bem especificados para a alfabetização e o ensino de língua portuguesa na etapa inicial do EF. Esse sujeito especificou questões linguísticas diretamente relacionadas ao objeto de ensino dessa etapa escolar - o ensino da linguagem -, entre os conhecimentos essenciais ao professor. Os demais desse grupo detiveram-se em questões do ensino em geral, expressão de atitudes e elementos da psicogênese.

Há décadas que a definição sobre o que ensinar nas aulas de língua materna passa por um desejo de alteração. Isso ocorre, em função das expectativas para esse aprendizado, na formação dos sujeitos, e dos resultados do ensino que se evidenciam nos frágeis desempenhos dos estudantes, em língua escrita, presenciados diariamente entre alunos dos diversos segmentos e anos de escolaridade, muitas vezes até de seus próprios professores. Aprender a escrita envolve saber ler, escrever e usar a língua com proficiência, em diferentes situações, incluindose aquelas que solicitam análises e posicionamentos e relações com o conhecimento. Nessa concepção, está expressa a categoria fundamental da língua, pela qual o objeto de ensino poderia ser assim definido:

[...] a leitura e a escrita, bem como os usos da língua em situações de instâncias públicas, que, em última análise, se orientam pela cultura escrita. Complementarmente, [...] estaria a reflexão sobre a língua, seu funcionamento e valores, os instrumentos de análise e reflexão linguística e a estética literária. (BRITTO, 2003, p. 50).

No ensino da alfabetização, apesar dos avanços teóricos sobre a aquisição da escrita e suas repercussões no psiquismo do sujeito (LURIA, 1988; VIGOTSKI, 2002; 2009), as discussões polarizam-se entre os métodos ditos tradicionais e as perspectivas articuladas à constituição simbólica do sistema de escrita, à compreensão e ao entendimento da linguagem como interação, com críticas aos métodos centrados no domínio das habilidades técnico-motoras da escrita, que ainda sobrevivem. A repercussão na alteração das práticas pedagógicas parece ter se restringido à substituição de materiais e atividades, mas nem sempre com mudanças efetivas nas concepções, não resultando em transformações no objeto, seu ensino e aprendizagem, como mostram os dados da pesquisa.

$\mathrm{Na}$ totalidade do campo da LM (com as denominações de português ou língua portuguesa), há um debate, na escola, concernente ao estatuto da gramática normativa nas atividades de ensino. Novas tendências de pesquisa, sustentadas na filosofia da linguagem e na ciência linguística (BAKHTIN, 2000; 2002; FARACO; CASTRO, 2008; GERALDI, 1997; SOARES, 2006; NEVES, 2002; TRAVAGLIA, 1996, entre outros), ressaltam a importância de alterar o foco da normatividade para o do funcionamento da língua na esfera da atividade humana, de considerar os laivos ideológicos da linguagem e ampliar as possibilidades de interação. O movimento de transformação, no entanto, continua vagaroso na escola, distante de considerar o conhecimento da função da língua, sua diversidade e possibilidades que apresenta às relações dos sujeitos entre si e com o conhecimento.

Gimeno Sacristán (1998) defende que os sistemas que enfrentam problemas para vencer o analfabetismo e domínios de proficiência em leitura e escrita devem trabalhar com a garantia de atuação da escola em aprendizagens básicas, delineadas por um currículo comum obrigatório. Assim, apesar da dificuldade inerente à definição de conteúdos de ensino e de todo condicionante ideológico que a acompanha, é necessário um consenso sobre capacidades e aprendizagens fundamentais que precisam ser alcançadas pelos alunos, com o ensino, considerada a função educativa da escola.

O processo de ensino e aprendizagem escolar implica a realização de importantes mediações, interações culturais, sociais e pedagógicas que visam à constituição de saberes pelos participantes. Cada área de ensino escolar se constitui e se movimenta por intermédio de saberes, que são o foco do trabalho cotidiano dos professores, e sua definição é um importante desafio. O autor define os conteúdos relevantes de uma matéria como aqueles que se compõem dos aspectos mais estáveis e das "[...] capacidades necessárias para [o sujeito] continuar tendo acesso e renovar o conhecimento adquirido." (GIMENO SACRISTÁN, 1998, p. 159). Os conteúdos "[...] não têm poder educativo por si mesmos [...]", e sua legitimidade somente se justifica "[...] enquanto forem suscetíveis de servir ao desenvolvimento dos indivíduos." (GIMENO SACRISTÁN, 1998, p.159).

Em todas as etapas da escolarização, o aprendizado da LM tem um papel relevante a desempenhar na constituição identitária dos sujeitos, porque a linguagem constitui material da consciência (BAKHTIN, 2002) - princípio de orientação fundamental aos processos de definição dos conteúdos de ensino da área, para que, usando 
palavras de Gimeno Sacristán (1998), pudessem servir ao desenvolvimento dos indivíduos.

4 CONCLUSÃO: formação do alfabetizador e políticas públicas

Neste trabalho, reconhece-se que, para além dos conteúdos específicos, a alfabetização precisa ser pensada também a partir dos contextos políticos, sociais e culturais em que ocorre. Pobreza e diversidade cultural podem marginalizar a população escolar, mas a escola é responsável pela transmissão e distribuição do conhecimento linguístico a todos os alunos. Quando se omite de ensinar as categorias essenciais da alfabetização, tratando-a como processo não científico, torna-se uma escola excludente. Na dimensão política, portanto, a escola precisa situar a alfabetização como uma ferramenta de transformação de situações de opressão social. Para isso, as políticas públicas precisam incidir no que é fulcral na escola: transformar as condições de intensificação e precarização do trabalho dos professores (FRIGOTTO, 1984). Tratando-se, especificamente, da questão linguística, há que se considerar que, pelo caráter ideológico intrínseco à linguagem, junto com as práticas desenvolvidas no seu ensino, os sentidos para ela concebidos e os conteúdos que veiculam também são ensinados (GERALDI, 1997).

$\mathrm{Na}$ dimensão epistemológica, a pesquisa evidenciou fragilidades na relação dos professores com os conhecimentos de língua materna, que deveriam incidir com clareza sobre o que é específico desse campo. Como afirma Kleiman (2001), a familiaridade com as questões linguísticas deveria ser integrante da identidade profissional do professor. Ao contrário, porém,

[...] o seu letramento, especialmente o da alfabetizadora, que introduz os alunos nas práticas socioculturais da sociedade letrada, é, cada vez mais, objeto de questionamento e especulação pela sociedade brasileira. (KLEIMAN, 2001, p. 39).

O destaque ao aspecto pedagógico, propriamente dito, o foco na metodologia e em atitudes, apresentados pelos sujeitos da pesquisa e sistematizados nos quadros, parecem demonstrar uma concepção simplista do ensino de LM, tratando-o como processo que poderia ser realizado sem muito conhecimento linguístico do professor. Conteúdo e metodologia não podem ser vistos como categorias independentes e dissociadas, pois o próprio objeto de ensino contém indicativos para a metodologia de trabalho. Os próprios conteúdos são mediadores da relação do indivíduo com a realidade, o que significa que o ensino precisa ser organizado e realizado de forma a promover a apropriação dos conceitos científicos, que se tornarão instrumentos mediadores culturais a atuarem no próprio processo de aprendizagem dos alunos (DAVÍDOV, 1988; VIGOTSKI, 2009).

A pesquisa identificou aspectos relevantes do conhecimento e da atuação dos professores e aponta para uma dimensão de conflito entre as necessidades de formação linguística nos anos iniciais do EF e as possibilidades dos professores que a efetuam. Ampliar as aprendizagens envolvidas na alfabetização é tarefa necessária da escola, que precisa levar em consideração os elementos culturais, políticos e econômicos que influenciam as atitudes e abordagens orientadoras do ensino e do trabalho dos professores. Os fatores que influenciam no esvaziamento de conhecimentos sobre alfabetização entre professores dos anos iniciais do EF permitem a integração do senso comum aos processos de ensino. A esse respeito, vale retomar a argumentação de Davídov (1988) sobre o aumento de uma instrução massiva, com revisão dos conteúdos, para diminuir a parte correspondente às bases da ciência, ou seja, a existência de uma simplificação de conteúdos e do ensino, para facilitar aos alunos, como se não estivessem ao alcance dos estudantes da classe trabalhadora (MARTSINKÉVICH ${ }^{12}$ apud DAVÍDOV, 1988). De interesse político, visando à preparação utilitária e pragmática, essa perspectiva exerce prejuízo duplo na formação das novas gerações: pela ausência do conteúdo e pela ausência do desenvolvimento mental que $\mathrm{o}$ aprendizado dos conteúdos científicos provoca.

Tais reflexões conduzem a problematizar a formação do alfabetizador. É inegável que essa formação precisa ocorrer em curso superior, mas qual seria o currículo apropriado? Quais as mediações necessárias para a apropriação de saberes específicos que orientem a prática educativa no ensino de língua materna?

Como subsídio ao processo de escolarização, mais que isso, como subsídio aos processos de desenvolvimento do psiquismo, da capacidade de crítica e posicionamento pessoal, o ensino de LM constitui uma instância indispensável para a escola reunir condições de exercer seu papel de contribuir à apropriação de bens culturais pela criança e ensinarIhe conhecimentos fundamentais para viver e atuar na sociedade. No contexto histórico atual, porém, em que a educação é submetida à lógica mercantil, via políticas de ordenamento aos ditames de organismos internacionais e agências financeiras que definem "[...] o risco país, os acordos das relações exteriores, [...] os incentivos fiscais.", e o Estado promove a "[...] associação dos objetivos educacionais com os da governabilidade." (LEHRER; MOTTA, 2012, p. 577578), pela subordinação aos ditames da eficácia, vigoram políticas de precarização da formação de professores e estudantes e das condições de trabalho na escola.

Nessa perspectiva, um olhar crítico sobre as políticas que envolvem a alfabetização, para além da duração temporal da organização escolar 
e da ampliação do acesso, desvela a carência da conjugação de políticas curriculares, políticas de formação de professores, investimentos substanciais em educação, enfim, de políticas que incidam na ossatura da escola e provoquem mudança na cultura pedagógica da alfabetização, com a formação linguística e integral do alfabetizador.

\section{REFERÊNCIAS}

ARELARO, L. R. G. Ensino fundamental no Brasil: avanços, perplexidades e tendências. Educação e Sociedade, Campinas, SP, v. 26, p. 1039-1066, 2005. Disponível em <http://www.scielo.br>. Acesso em 12, ago. 2013.

BAKHTIN, M. Estética da criação verbal. São Paulo: Martins Fontes, 2000.

Marxismo e filosofia da linguagem. São Paulo: Hucitec, 2002.

BRASIL. Ministério da Educação. Resolução CNE/ CEB $n^{\circ} 4$, de 13 de julho de 2010. Define Diretrizes Curriculares Nacionais Gerais para a Educação Básica. Diário Oficial da União, Brasília, DF, 2010, Seção 1, p. 824.

Secretaria de Educação Básica. Pró-letramento: programa de formação continuada de professores dos anos/séries iniciais do ensino fundamental: alfabetização e linguagem. Brasília, DF, 2008.

. Presidência da República. Lei n 11.274, de 06 de fevereiro de 2006. Altera a redação dos arts. 29, 30, 32 e 87 da Lei n 9.394 de 20 de dezembro de 1996, que estabelece as diretrizes e bases da educação nacional, dispondo sobre a duração de 9 (nove) anos para o ensino fundamental, com matrícula obrigatória a partir dos 6 (seis) anos de idade. Diário Oficial da União, Brasília, DF, 2006.

BRITTO, L. P. L. de. Alfabetismo e educação escolar. In: SILVA, E. T. da (Org.). Alfabetização no Brasil: questões e provocações da atualidade. Campinas, SP: Autores Associados, 2007. p. 19-34.

Contra o consenso: cultura escrita, educação e participação. Campinas, SP: Mercado de Letras, 2003.

CHARMEUX, E. Aprendendo a ler: vencendo o fracasso. São Paulo: Cortez, 1994.

DAVÍDOV, V. A atividade de estudo na idade escolar inicial. In: La ensenanza escolar y el desarrolo psíquico: investigación psicológica teórica y experimental. Moscou: Editorial Progreso, 1988. p. $158-191$.

FARACO, C. A.; CASTRO, G. de. Por uma teoria linguística que fundamente o ensino de língua materna (ou de como apenas um pouquinho de gramática nem sempre é bom). Educar em Revista, Curitiba, v. 15, p. 1-09, 1999. Disponível em:<http:// www.educaremrevista.ufpr.br/arquivos_15/faraco castro.pdf>. Acesso: 14 mar. 2008.

FRADE, I. C. A. da S. Alfabetização na escola de nove anos: desafios e rumos. In: SILVA, E. T. da (Org.). Alfabetização no Brasil: questões e provocações da atualidade. Campinas, SP: Autores Associados, 2007. p. 73-112.

FRIGOTTO, G. A produtividade da escola improdutiva: um (re) exame das relações entre educação e estrutura econômico-social capitalista. São Paulo: Cortez, 1984.

GERALDI, J. W. Portos de passagem. São Paulo: Martins Fontes, 1997.

GIMENO SACRISTÀN, J. Compreender e transformar o ensino. 4. ed. Trad. Ernani F. da Fonseca. Porto Alegre: Artmed, 1998.

INSTITUTO NACIONAL DE ESTUDOS E PESQUISAS EDUCACIONAIS ANÍSIO TEIXEIRA. PISA 2009. Brasília, DF, 2011. Disponível em: <http:// www.inep.gov.br/home>. Acesso em: 10 abr. 2011.

KLEIMAN, A. A formação do professor: perspectivas da linguística aplicada. São Paulo: Mercado de Letras, 2001.

LEHRER, R.; MOTTA, V. C. da. Políticas educacionais neoliberais e educação do campo (verbete). In: CALDART, R. S. et al. (Orgs.). Dicionário da educação do campo. Rio de Janeiro: Escola Politécnica de Saúde Joaquim Venâncio; São Paulo: Expressão Popular, 2012. p. 576-585.

LEONTIEV, A. N. Uma contribuição à teoria do desenvolvimento da psique infantil. In: VIGOTSKII, L. S., LURIA, A. R., LEONTIEV, A. N. Linguagem, desenvolvimento e aprendizagem. Trad. de Maria da Penha Villalobos. São Paulo: Ícone: Edusp, 1988. p. 59-83.

LURIA, A. R. O desenvolvimento da escrita na criança. In: VIGOTSKII, L. S.; LURIA, A. R.; LEONTIEV, A. N. Linguagem, desenvolvimento e aprendizagem. Trad. de Maria da Penha Villalobos. São Paulo: Ícone: Edusp, 1988. p. 143-189.

MACIEL, F. I. P.; BAPTISTA, M. C.; MONTEIRO, S. M. (Orgs.). A criança de 6 anos, a linguagem escrita e o ensino fundamental de nove anos: 
orientações para o trabalho com a linguagem escrita em turmas de crianças de seis anos de idade. Belo Horizonte: UFMG/FaE/CEALE, 2009.

NEVES, M. H. de M. Gramática na escola. São Paulo: Contexto, 2002.

SOARES, M. Letramento: um tema em três gêneros. 2. ed. Belo Horizonte: Autêntica, 2006.

TRAVAGLIA, L. C. Gramática e interação: uma proposta para o ensino de gramática no $1^{\circ}$ e $2^{\circ}$ graus. São Paulo: Cortez, 1996.

VIGOTSKI, L. S. A construção do pensamento e da linguagem. Trad. Paulo Bezerra. 2. ed. São Paulo: Martins Fontes, 2009.

A formação social da mente: o desenvolvimento dos processos psicológicos superiores. 6. ed. São Paulo: Martins Fontes, 1998.

Obras escogidas. 2. ed. Madri: Visor, 2000. Tomo III.

\section{NOTAS}

1 A psicologia histórico-cultural indica a existência de atividades específicas pelas quais ocorre a relação individual do sujeito com a realidade social e que orienta o desenvolvimento do psiquismo humano, nas suas diversas fases (atividade orientadora ou principal ou dominante). No início da idade escolar, as crianças realizam muitas atividades, mas a orientadora e impulsionadora do desenvolvimento é a atividade de estudo (DAVÍDOV, 1988).

2 Pensamento que deixa de se apoiar exclusivamente no real empírico e passa a apoiar-se no próprio pensamento, na consciência, por isso, profundamente mediatizado e analítico.

3 Operação mental; envolve relações entre diferentes objetos de pensamento.

4 Unidades de abstração e generalização do objeto de pensamento e dos conceitos teóricos.

5 Para Vigotski (2009), o desenvolvimento dos conceitos científicos supõe o desenvolvimento de capacidades intelectuais, como atenção deliberada, memória lógica, abstração, capacidade de relacionar, comparar e diferenciar. Os conceitos científicos originam-se com o ensino formal disponibilizado pela educação escolar e se organizam num sistema hierárquico de relações. Todo conteúdo escolar é constituído de uma série de informações, dados e fatos articulados entre si, segundo uma ordem interna, que deverá ser compreendida pelo aprendiz e que desenvolverá suas habilidades. As operações com conceitos científicos demandam o foco de atenção no próprio ato de pensamento; a operação com conceitos cotidianos, somente que se focalize o objeto. formação do alfabetizador

6 Ação Civil Pública, ACP nº. 402/2007-MP/PR, pela qual o Ministério Público/PR intervém na reforma educacional, ao permitir a matrícula no EF de 09 anos de crianças que completem seis anos no decorrer do ano letivo, e não apenas até seu início. Essa decisão motiva e legitima a inclusão de muitas crianças com apenas cinco anos de idade - muitas vezes até o final do ano letivo - no EF.

7 Relacionadas às atividades orientadoras do desenvolvimento psíquico, confira a nota 1.

8 Vigotski (2000) denomina de críticos os momentos em que ocorrem saltos qualitativos no desenvolvimento da criança.

9 Muitas vezes, a palavra discurso é interpretada pelo senso comum ou com sentido indefinido. A partir de Bakhtin (2002), refere-se às significações em movimento nos processos de interação verbal, que são atravessados pelas ideologias dos sistemas em que se situam. Os discursos participam do fluxo social em constante participação na constituição da atividade mental, nunca podem ser compreendidos fora da situação social que os engendra. Quando se referem a atividades mentais isoladas, abstraídas do sentido haurido no social, perdem a sua modelagem ideológica e seu grau de consciência, tornando-se formas estereotipadas (BAKTIN, 2002). Há diferentes níveis de discurso, de acordo com o contexto cultural e nível de constituição da consciência de quem o emite.

10 Indícios dessa possibilidade encontram-se na forma impessoal e denotadora de distanciamento com que a maioria respondeu (apenas quatro responderam em primeira pessoa) e também na reprodução do discurso de documentos oficiais.

11 Não há sujeitos no $3^{\circ}$ ano da organização do EF em 08 anos. Os 04 sujeitos da coluna Todos já tinham lecionado em todos os anos da etapa inicial do EF. 03 encontravam-se em função de coordenação pedagógica e 01 na de professora de literatura, na época da pesquisa.

12 O autor refere-se a: MARTSINKÉVICH, V. La instrucción en los EE.UU.: importancia econômica y eficacia. Moscú, 1967, p. 69.

\section{Benedita de Almeida}

Graduada em Letras

Doutora em Educação pela Universidade de São Paulo (USP)

Professora Associada do Curso de Pedagogia e do Programa de Pós-Graduação em Educação (PPGEFB) da Universidade Estadual do Oeste do Paraná (UNIOESTE) E-mail: beneditaalmeida@yahoo.com.br

Universidade Estadual do Oeste do Paraná - UNIOESTE Rua Maringá, 1200 - Vila Nova - Francisco Beltrão-PR CEP: 85605-010 